\title{
Quantitative mass spectrometry analysis reveals a panel of nine proteins as diagnostic markers for colon adenocarcinomas
}

\author{
Apurva Atak ${ }^{1}$, Samiksha Khurana ${ }^{1}$, Kishore Gollapalli ${ }^{1}$, Panga Jaipal Reddy ${ }^{1}$, Roei \\ Levy², Stav Ben-Salmon ${ }^{2}$, Dror Hollander ${ }^{2}$, Maya Donyo ${ }^{2}$, Anke Heit ${ }^{3}$, Agnes Hotz- \\ Wagenblatt ${ }^{3}$, Hadas Biran ${ }^{4}$ Roded Sharan ${ }^{4}$ Shailendra Rane ${ }^{5}$, Ashutosh Shelar ${ }^{5}$, \\ Gil Ast ${ }^{2}$ and Sanjeeva Srivastava ${ }^{1}$

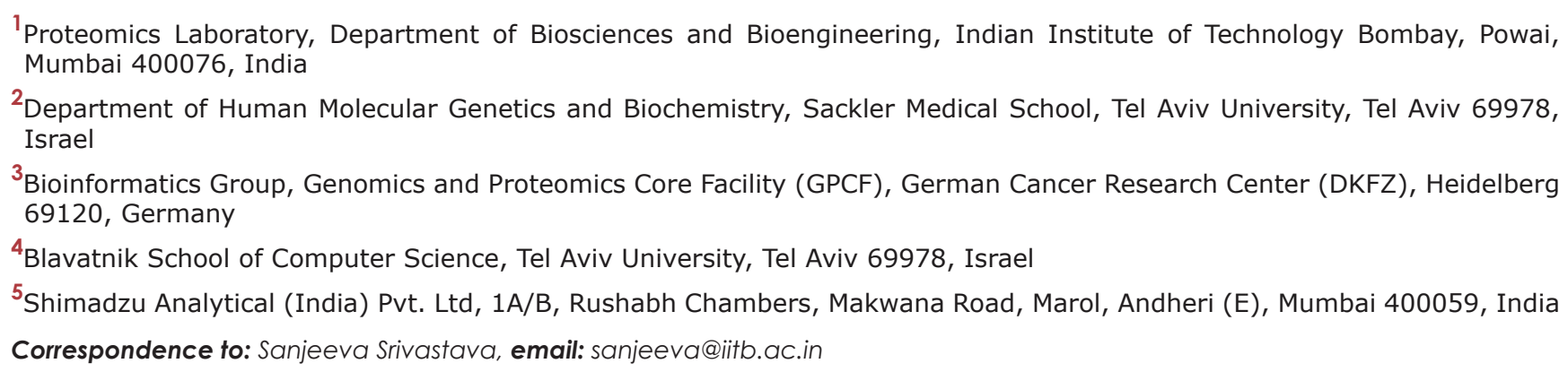
Keywords: colon adenocarcinoma; proteomics; biomarkers; tissue; iTRAQ

Received: July 14, $2017 \quad$ Accepted: January 30, $2018 \quad$ Published: February 05, 2018

Copyright: Atak et al. This is an open-access article distributed under the terms of the Creative Commons Attribution License 3.0 (CC BY 3.0), which permits unrestricted use, distribution, and reproduction in any medium, provided the original author and source are credited.

\section{ABSTRACT}

Adenocarcinomas are cancers originating from the gland forming cells of the colon and rectal lining, and are known to be the most common type of colorectal cancers. The current diagnosis strategies for colorectal cancers include biopsy, laboratory tests, and colonoscopy which are time consuming. Identification of protein biomarkers could aid in the detection of colon adenocarcinomas (CACs). In this study, tissue proteome of colon adenocarcinomas $(n=11)$ was compared with the matched control specimens $(n=11)$ using isobaric tags for relative and absolute quantitation (iTRAQ) based liquid chromatography-mass spectrometry (LC-MS/MS) approach. A list of $\mathbf{2 8 5}$ significantly altered proteins was identified in colon adenocarcinomas as compared to its matched controls, which are associated with growth and malignancy of the tumors. Protein interaction analysis revealed the association of altered proteins in colon adenocarcinomas with various transcription factors and their targets. A panel of nine proteins was validated using multiple reaction monitoring (MRM). Additionally, S100A9 was also validated using immunoblotting. The identified panel of proteins may serve as potential biomarkers and thereby aid in the detection of colon adenocarcinomas.

\section{INTRODUCTION}

Colorectal cancer is one of the most common cancers detected worldwide, with around 1.4 million cases diagnosed in 2012 [1]. Adenocarcinomas are the most common type of colon cancers, whereas small fraction of lymphoma and squamous cell carcinoma cases can also be found. Removal of high-risk adenomas and tumors at early stage of colorectal cancer (CRC) can avert the onset/ progression into higher grades of cancer. Early diagnosis shows a 5 -year survival rate among $90 \%$ patients with localized tumors, whereas it drops down to less than $10 \%$ when the CRC is metastasized to other organs [2,3]. This makes the implementation of screening methods aimed at early detection paramount for reducing mortality rate.

At present, the CRC screening methods range from a simple stool test to highly invasive colonoscopy [4]. Major limitations in the early diagnosis of colon cancers 
are low sensitivity of existing diagnostic methods, cost and access to the modern imaging techniques like computed tomography (CT) and magnetic resonance colonography. There is a need for more specific and sensitive molecular tests than the currently available diagnostic methods [5]. The ideal approach would be to discover and validate genetic and/or protein biomarkers which could serve as an efficient tool for cancer screening, diagnosis of recurrences and prognosis.

Identification of novel biomarkers for colorectal cancer with both- prognostic and predictive value, not only aids in improving our understanding of the disease but also helps in the treatment of disease at an early stage, and management at an advanced stage. This not only offers new tools to estimate disease outcome but also helps in predicting overall patient outcome. Over the years, several tissue and serum specific biomarkers have been identified. Histological evaluation of tissue samples from gastrointestinal neoplasms are commonly carried out by immunohistochemistry (IHC) analysis of target proteins against CDX2 [6], Mucins (MUC2) [7], Special AT-rich sequence binding protein 2 (SATB2) [8], Cytokeratins $[9,10], \beta$-catenin [11], Carcinoembryonic antigen (CEA) [12], and Cadherin 17 [13, 14]. Furthermore, protein targets like CDX2 and SATB2 have also been linked to be important prognostic markers for colorectal cancer patients. For instance, loss of CDX2 expression has been commonly associated with proximal location, advanced $\mathrm{T}, \mathrm{N}, \mathrm{M}$, overall stage; and has been considered as an independent poor prognostic marker of overall survival and progression-free survival [15]. Besides performing tests on faeces, several tests against tumor associated antigens as potential biomarkers in early diagnosis have also been identified. In this regard, Serum CEA and $\mathrm{Ca}$ 19.9 have been commonly used as classical tumor markers in colorectal cancer patients. Several studies support the prognostic value of high pre-operative CEA levels as a surrogate for useful investigation [16-19]. Additionally, besides being more cost effective than radiological detection methods, CEA is also the most frequent determinant of recurrence in asymptomatic patients [20]. An increase in Ca 19.9 levels, an alternate marker for colorectal cancers, has been significantly associated with higher frequency of metastasis and lower survival rates, thereby making it prognostic marker for adverse colorectal cancer patients [20]. Hence, there is a need of other novel biomarkers which could improve patient outcome.

This study aimed at investigating proteomic alterations in human CAC tissues from a heterogeneous patient population using isobaric tagging for relative and absolute quantification (iTRAQ) to identify potential biomarkers. The identified panel of proteins was validated by Multiple Reaction Monitoring (MRM) assays. Further bioinformatic analysis aided in understanding the biological networks associated with the disease pathogenesis.

\section{RESULTS}

\section{Identification of differentially expressed proteins in iTRAQ labelled colon adenocarcinoma tissue lysates}

The CAC tumor and their matched control tissue lysates were digested using trypsin followed by iTRAQ labelling. Each of the four 4-plex reactions had a pool of all the control tissue lysates $(n=11)$ labelled with the iTRAQ label 114 and three of the individual tumor tissue lysates labelled using 115, 116 and 117 iTRAQ labels. Additionally, one of the four sets consisted of the pool of all the tumor tissue lysates $(n=11)$ labelled with the iTRAQ label 117. The iTRAQ labelled samples were pooled and subjected to off-gel fractionation followed by LC-MS/MS. The LC-MS/MS data was analyzed independently by Spectrum Mill (SM). 514, 354, 569 and 581 proteins were identified with 2 or more unique peptides in set 1 , set 2 , set 3 and set 4 respectively, of the iTRAQ labelled samples from SM analysis. Of these, 401 proteins were common in at least 3 out of 4 sets (Supplementary Table 1A). Further, 285 proteins passed an average fold change cut-off of 1.5 and 147 proteins followed the same trend of dysregulation in at least 7 of the 11 patients (64\% population). A representative mass spectrum for Decorin, which is down-regulated in CACs, has been shown in Figure 1.

In order to increase our confidence of the proteins identified using Spectrum Mill, the raw files from the LC-MS/MS run were also analysed using the TransProteomice Pipeline (TPP) software [21]. 944, 725, 1040 and 1099 proteins were identified with 2 or more peptides in set 1 , set 2 , set 3 and set 4 , respectively from TPP. 808 proteins were common in at least 3 out of the 4 sets (Supplementary Table 1B), of which, 510 proteins passed an average fold change cut-off of 1.5 ; and 232 proteins followed the same trend of dysregulation in at least 7 of the 11 patients.

These 232 proteins were compared with the 147 proteins from Spectrum Mill dataset, which passed all the criteria, and a list of 94 proteins was generated which were common between Spectrum Mill and Trans-Proteomic Pipeline dataset (Supplementary Table 1C). This list of 94 significantly altered proteins was compared with the literature on CACs and CRCs reported by Jankova et $a l$. and Wisniewski et al. to identify the overlap [22, 23] (Supplementary Table 1D). Additionally, comparison of results from current study with the data from Zhang et al. [24] at CPTAC data portal (https://cptac-data-portal. georgetown.edu/cptacPublic/) revealed 34 common proteins exhibiting same trends in both the data sets (Table 1). Peptide transitions for these 34 proteins were studied using TPP, SM, SRM atlas and Skyline. The list of 94 proteins identified to be significantly dysregulated from this study was compared for expression levels of these 
proteins in colorectal tumor tissues available at the HPA. Protein expression was listed in HPA as High, Medium, and Low or Not detected. Proteins showing medium or high expression in $\geq 50 \%$ population were considered to be significantly up-regulated. With this comparison, 18 of the 94 proteins were found to be up-regulated in SM as well as TPP analysis, CPTAC and HPA data. 3 of these proteins were included in validation by MRM. Additionally, another 36 proteins were found to be altered with same trend of dysregulation in SM and TPP analysis as that from the HPA data.

\section{Pathways analysis using dysregulated proteins from spectrum mill and Trans-Proteomic Pipeline dataset}

Significantly dysregulated proteins showing the same trend in at least 7 out of 11 patients identified using TPP and SM software were combined to identify 285 unique proteins. These proteins were submitted as input list to identify the alterations in the underlying pathways using the Database for Annotation, Visualization and Integrated Discovery (DAVID) Functional Annotation
Bioinformatics Analysis v6.8 [25, 26]. Most of the upregulated proteins were associated with glycolysis, pentose phosphate pathway, pyruvate metabolism, protein processing, antigen processing and presentation, spliceosome, proteosome mediated protein degradation and ribosomal proteins while the down-regulated proteins were associated with focal adhesions and proteoglycans in cancer (Supplementary Table 1E; Figure 1).

\section{Immunoblotting for S100A9 protein expression in colon adenocarcinoma}

Tumor and control tissue levels of S100A9 protein were validated using immunoblotting method. Housekeeping proteins such as beta actin and GAPDH were found to be differentially expressed from the shotgun proteomics study. Therefore, S100A9 expression levels were normalised against a uniform band (approx. $70 \mathrm{kDa}$ ) from the ponceau image obtained post transfer of the samples on the PVDF membrane. After normalisation, S100A9 was found to be up-regulated in all the tumor samples compared to its controls with $p$ value $<0.05$, which was consistent with the iTRAQ analysis (Figure 2).
A

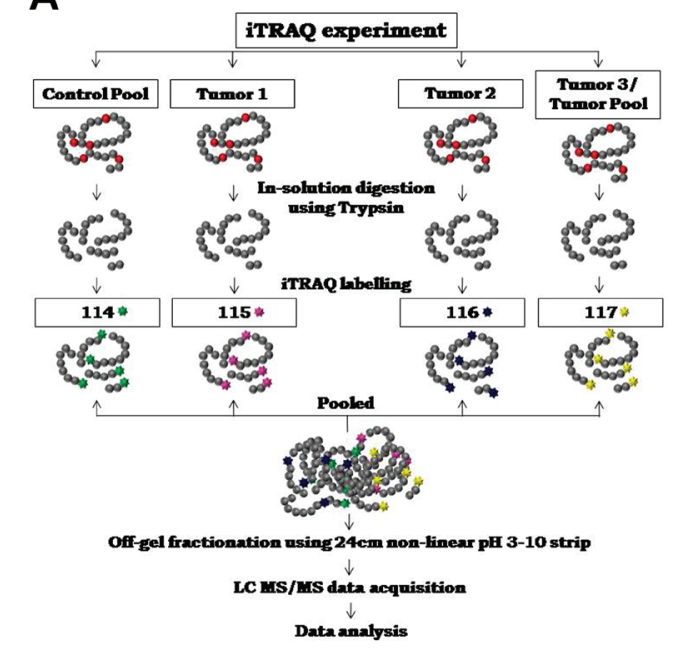

B

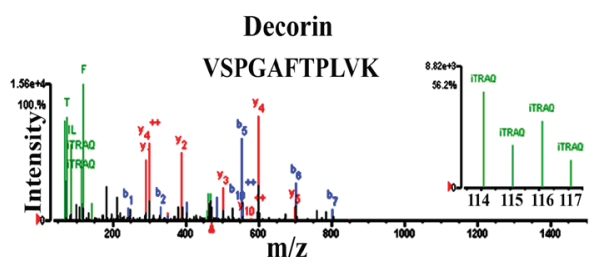

C
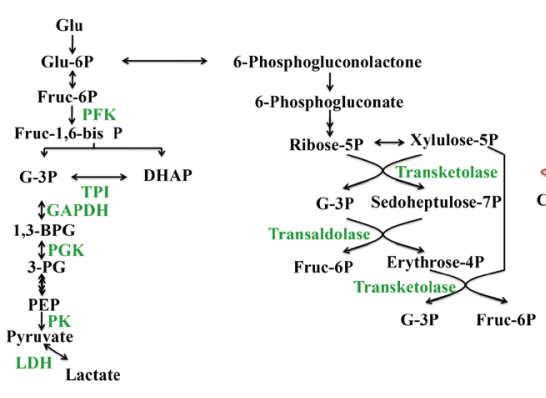

D

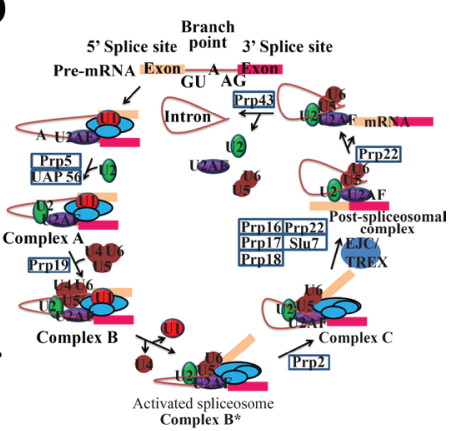

E

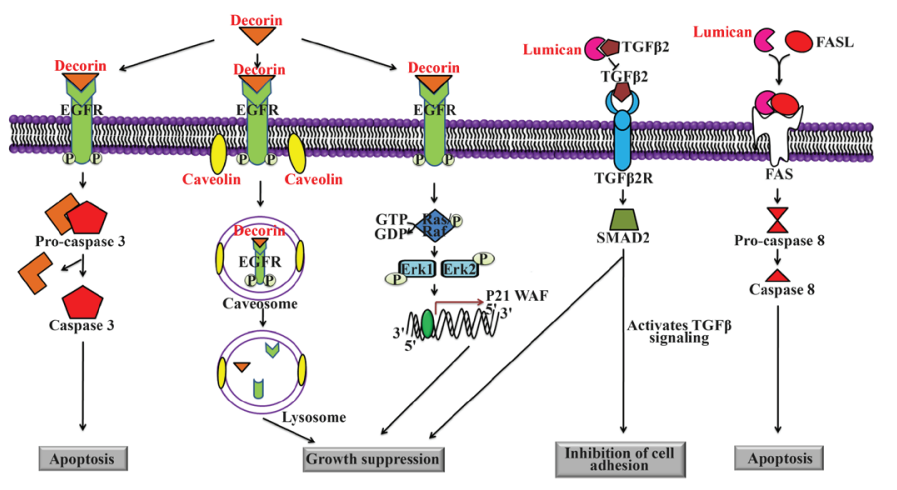

Figure 1: Quantitative proteomic analysis of human colon adenocarcinomas and the significantly altered metabolic pathway. (A) Schematic representation of the iTRAQ labelling strategy and the mass spectrometry based approach used for the identification of proteomic alterations in colon adenocarcinoma tissue lysates. (B) Representative spectra for proteins identified to be altered in colon adenocarcinoma tissue lysates (Decorin spectra was used for representation). Significantly altered proteins identified from iTRAQ based mass spectrometry experiments were subjected to pathway analysis using Database for Annotation, Visualization and Integrated Discovery (DAVID) Functional Annotation Bioinformatics Analysis v6.8, an online tool, which revealed (C) Glycolysis (D) Spliceosome mediated splicing and (E) Proteoglycan mediated signaling to be majorly altered in colon adenocarcinomas. 
Table 1: List of differentially expressed proteins obtained from TPP and spectrum mill analysis and following the same trend in the literature (Zhang et al., 2014).

\begin{tabular}{|c|c|c|c|c|c|c|}
\hline \multicolumn{3}{|c|}{ Protein details } & \multicolumn{3}{|c|}{ Average fold change (Tumor/Normal) } & \multirow{2}{*}{$\begin{array}{c}\text { p-value } \\
\text { Computed } \\
\text { from TPP } \\
\text { data }\end{array}$} \\
\hline $\begin{array}{l}\text { Accession } \\
\text { number }\end{array}$ & Protein name & Gene name & TPP & $\begin{array}{c}\text { Spectrum } \\
\text { mill }\end{array}$ & CPTAC & \\
\hline P06702* & Protein S100-A9 & S100A9 & 3.2 & 3 & 7.9 & 0.00034 \\
\hline P05109* & Protein S100-A8 & S100A8 & 3.2 & 2.8 & 6.4 & 0.00088 \\
\hline P08195 & 4F2 cell-surface antigen heavy chain & SLC3A2 & 3 & 2.8 & 1.6 & 0.00100 \\
\hline P61626 & Lysozyme C & LYZ & 2.8 & 2.8 & 4.1 & 0.00143 \\
\hline P05164 & Myeloperoxidase & MPO & 2.2 & 2.3 & 2.3 & 0.00145 \\
\hline P11940 & Polyadenylate-binding protein 1 & PABPC1 & 2.2 & 2.4 & 1.5 & 0.00032 \\
\hline P31949* & Protein S100-A11 & S100A11 & 2.1 & 2.3 & 1.7 & 0.00029 \\
\hline P78527 & $\begin{array}{l}\text { DNA-dependent protein kinase catalytic } \\
\text { subunit }\end{array}$ & PRKDC & 2 & 2.9 & 39.9 & 0.00023 \\
\hline Q14103 & Heterogeneous nuclear ribonucleoprotein D0 & HNRNPD & 2 & 2 & 23.9 & 0.00581 \\
\hline Q12906 & Interleukin enhancer-binding factor 3 & ILF3 & 2 & 2 & 13.2 & 0.00005 \\
\hline P49327 & Fatty acid synthase & FASN & 2 & 2.1 & 1.6 & 0.00145 \\
\hline Q07955 & Serine/arginine-rich splicing factor 1 & SRSF1 & 1.9 & 1.8 & 10.8 & 0.00380 \\
\hline P00338* & L-lactate dehydrogenase A chain & LDHA & 1.9 & 1.9 & 3.5 & 0.00152 \\
\hline P50454 & Serpin H1 & SERPINH1 & 1.9 & 2.2 & 2.8 & 0.00010 \\
\hline P61247 & 40S ribosomal protein $\mathrm{S} 3 \mathrm{a}$ & RPS3A & 1.9 & 2 & 1.8 & 0.00093 \\
\hline O60506 & Heterogeneous nuclear ribonucleoprotein Q & SYNCRIP & 1.9 & 1.7 & 1.8 & 0.00529 \\
\hline P40121 & Macrophage-capping protein & CAPG & 1.8 & 1.9 & 9.6 & 0.00054 \\
\hline P07108 & Acyl-CoA-binding protein & DBI & 1.8 & 2 & 5.8 & 0.00622 \\
\hline P60842 & Eukaryotic initiation factor 4A-I & EIF4A1 & 1.8 & 2 & 3.1 & 0.00476 \\
\hline P51858* & Hepatoma-derived growth factor & HDGF & 1.8 & 1.9 & 2.9 & 0.00007 \\
\hline O14980 & Exportin-1 & XPO1 & 1.8 & 2.2 & 2 & 0.01283 \\
\hline P29401 & Transketolase & TKT & 1.7 & 2 & 68 & 0.00066 \\
\hline P14618* & Pyruvate kinase & PKM & 1.7 & 1.6 & 34.5 & 0.00038 \\
\hline P06748 & Nucleophosmin & NPM1 & 1.6 & 2.1 & 42.4 & 0.00697 \\
\hline P26599 & Polypyrimidine tract-binding protein 1 & PTBP1 & 1.6 & 1.6 & 33.6 & 0.00120 \\
\hline P78417 & Glutathione S-transferase omega-1 & GSTO1 & 1.6 & 2.1 & 26.2 & 0.00160 \\
\hline P51884* & Lumican & LUM & 0.6 & 0.6 & 0.6 & 0.00013 \\
\hline P12277 & Creatine kinase B-type & CKB & 0.6 & 0.7 & 0.2 & 0.01292 \\
\hline P07585 & Decorin & $\mathrm{DCN}$ & 0.5 & 0.5 & 0.6 & 0.00001 \\
\hline Q9NZN4* & EH domain-containing protein 2 & EHD2 & 0.5 & 0.6 & 0.5 & 0.02325 \\
\hline Q16853* & Membrane primary amine oxidase & $\mathrm{AOC} 3$ & 0.5 & 0.5 & 0.4 & 0.01800 \\
\hline P00918 & Carbonic anhydrase 2 & CA2 & 0.5 & 0.5 & 0.1 & 0.00720 \\
\hline P00915 & Carbonic anhydrase 1 & CA1 & 0.5 & 0.7 & 0.1 & 0.01223 \\
\hline O14558 & Heat shock protein beta- 6 & HSPB6 & 0.4 & 0.4 & 0.6 & 0.01205 \\
\hline
\end{tabular}

* Proteins validated using MRM.

\section{Validation of differentially expressed proteins identified from the iTRAQ approach in colon adenocarcinoma tissue lysates using multiple reaction monitoring}

Peptide sequences of 13 potential protein biomarkers were taken forward for MRM-based validation in 10 of the 11 CAC tissue lysates included in iTRAQ study. Total 46 peptides were shortlisted for the nine proteins, of which only 27 peptides corresponding to 9 proteins were detected in the tissue lysates and their retention times are given in Supplementary Table 1F.

MS stats R-package was used to perform statistical analysis to identify and quantify the significantly dysregulated proteins. Proteins showing fold change $\geq 1.5$ and $p$-value of $\leq 0.05$ were categorised as significantly 
altered proteins. All nine proteins showed significant dysregulation in CAC versus their matched control (Table 1). HDGF, LDHA, PKM, S100A8, S100A9 and S100A11 were found to be significantly up-regulated and EHD2, LUM and AOC3 were found to be significantly down-regulated in CAC versus their matched control (Figure 2). The MRM measurements of all nine target proteins were found to be consistent with the data obtained from the iTRAQ based proteomics experiment, which could be potential markers for diagnosing CACs.

\section{Finding associated protein-protein interaction on a background network}

We adapted the propagation procedure described in Vanunu et al. 2010 [27] to identify additional disease

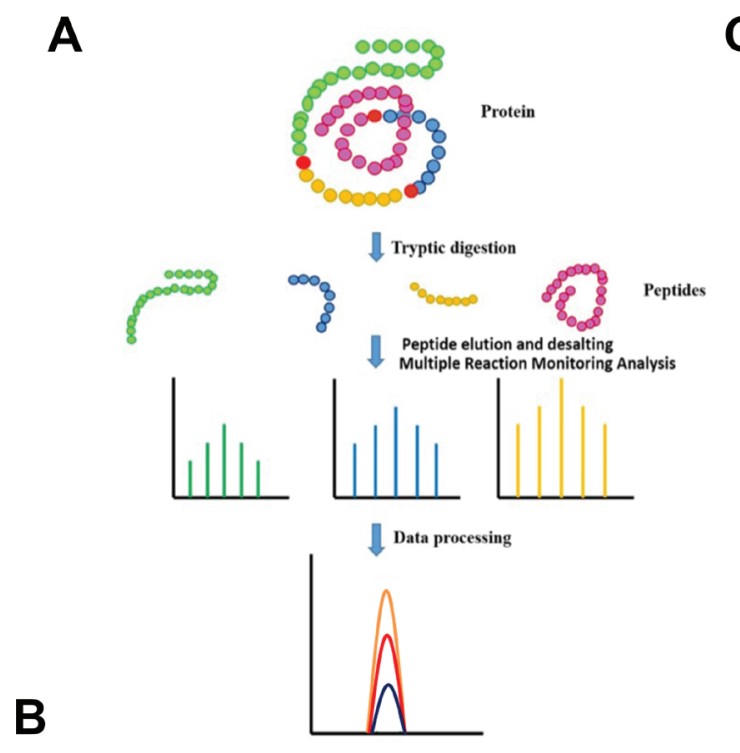

S100-A9 (SEQUENCE : MSQLER )

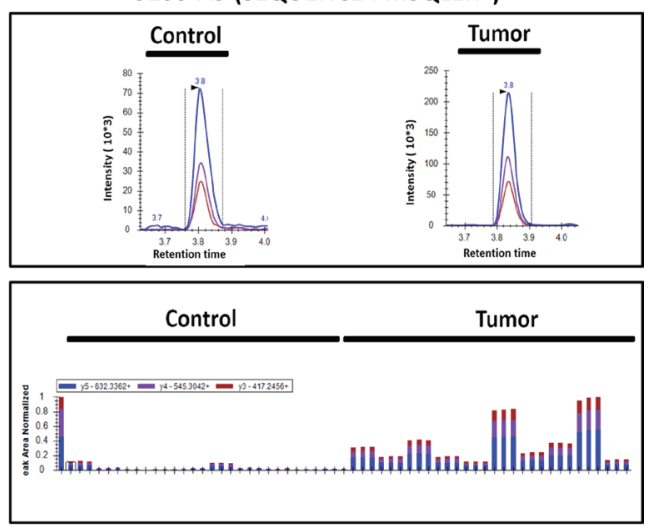

PKM (SEQUENCE : APIIAVTR )
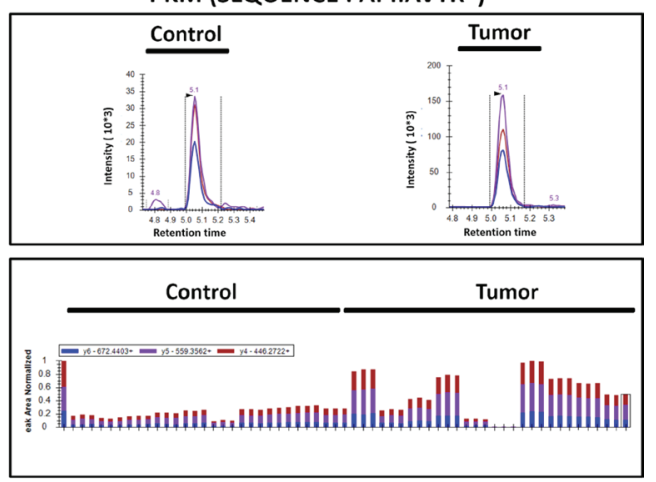

E
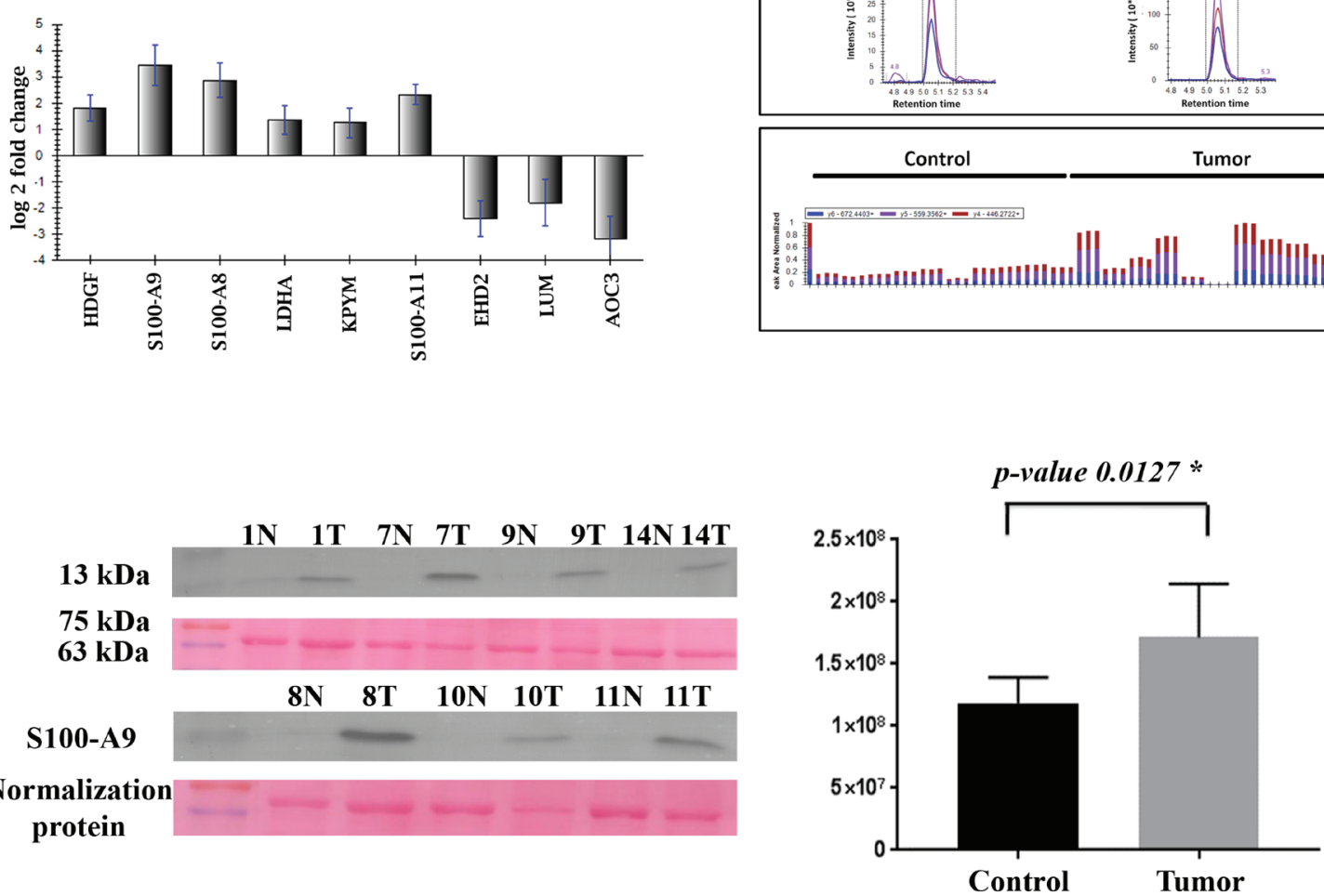

Figure 2: MRM and immunoblotting based validation of the top dysregulated proteins identified in the present study. (A) Schematic representation of the MRM workflow. (B) Graphical representation of the Log2 fold change of differentially expressed proteins identified using MRM. (C and D) Representative chromatograms depicting transitions for peptides specific to S100-A9 and Pyruvate kinase proteins, respectively. (E) Validation of expression levels of S100-A9 protein in colon adenocarcinoma tissue lysates and their matched controls using immunoblotting. 
related proteins. Briefly, a list of prior-knowledge proteins was diffused over a background network-here, the HIPPIE protein-protein interaction (PPI) network [28] - and a pre-defined cut-off based on relatedness score was used to choose the strongest first degree neighbours. We separately propagated the up- and down-regulated proteins as they appear in the list of 285 proteins discovered by TPP and/or SM, as discussed above (Figure 3). To find the strongest common top 20 proteins for this list, we pooled together the up and down-regulated proteins and obtained the 50 strongest PPI interactions. We then propagated each protein separately and obtained the 50 strongest PPI interactions. Then, we intersected the resulting lists and picked the top 20 strongest interactions. Figures $3 \mathrm{~A}$ and $3 \mathrm{~B}$ show the interactions - as links, color coded by common functions, which we manually derived from the literaturebetween the 20 post-proteins (colored names) and the 285 prior-proteins (grey hues). In the 20 post-proteins list, some notable members like NTRK1 (common to $163 / 285$ proteins; see Supplementary Table $1 \mathrm{G}$ for a list of scores and number of common proteins for each of the 20 proteins), SUMO2 and SUMO1 (common to 160 and $111 / 285$ proteins, respectively), JUN (common to 143/285 proteins), and TP53 (common to 91/285 prior proteins) are associated with tumor pathobiology.

\section{DISCUSSION}

$\mathrm{CAC}$ is one of the major causes of cancer related deaths. Cancers are developed due to the manifestation of mutations in various proto-oncogenes and oncogenes, which can be identified using genomics. However, phenotype of the cells is majorly decided by the protein expression, their modifications and interaction. Hence, studying the cancers at proteome level would yield plausible markers for the disease diagnosis/prognosis/ therapy [29].

Previously, Fung et al. reported a three protein panel as blood-based biomarkers for the diagnosis of colorectal cancers. The panel consists of Insulin-like growth factorbinding protein 2 (IGFBP2), Dickkopf-related protein 3 (DKK3) and Pyruvate kinase (PKM2), which could detect the CRCs with a sensitivity of $73 \%$ and specificity of $95 \%$ [30]. Later in the year of 2016, Jones et al. identified a panel of 13 proteins (15 transitions), from the plasma specimens of CRC patients using multiple reaction monitoring (MRM) based mass spectrometry approach, which could discriminate the CRCs from controls with a sensitivity of $87 \%$ and specificity of $81 \%$ [31]. In another study, Blume et al. identified the plasma proteomic alterations in colorectal cancers and validated a panel of eight proteins using ELISA as diagnostic markers for CRCs, while another panel consisting of four proteins was proposed as a biomarker panel for advanced adenomas [32]. In the current study, iTRAQ based tissue proteomic analysis of $\mathrm{CAC}$ and matched controls revealed alteration in proteins involved in various metabolic and biological processes, which affect the growth and development of tumors. Comparison of our current study results with the existing mRNA/protein expression data would help to identify protein markers with high confidence. In this light, protein expression data from our study was compared with IHC data from HPA and label-free mass spectrometry data from Clinical Proteomic Tumor Analysis Consortium Components (CPTAC) for CRCs and most of the identified proteins in the present study are in sync with the HPA and CPTAC studies for CRCs (Supplementary Table $1 \mathrm{H}$ ).

In order to maintain high proliferation rates, tumor cells require large amounts of ATP and precursors for the synthesis of nucleic acids. Tumor cells often exhibit increased flux of glucose into glycolysis to generate ample amounts of ATP. To continue the glycolysis process without interruption, cancer cells increase the expression of lactate dehydrogenase, which converts the end product of glycolysis (pyruvate) to lactate [33]. The $\mathrm{H}+$ ions generated in this process decreases the $\mathrm{pH}$ of the tumor microenvironment, thereby making way for the tumor cells to grow by killing the adjacent /nearby cells. This acidic environment facilitates tumor growth, invasion and metastasis in malignant cancers [34]. In the present study, most of the glycolysis and pentose phosphate pathway proteins were found to be up-regulated. Increased levels of these proteins might be useful in increasing flux of glucose into glycolysis and pentose phosphate pathway, thus aiding in tumor growth and malignancy. Pyruvate kinase (PKM) and lactate dehydrogenase A chain, which are associated with the glucose metabolism were found to be significantly increased in the CACs from the present study. Pyruvate kinase is the last enzyme in the glycolysis pathway, which converts phosphoenol pyruvate to pyruvate and an ATP molecule is released in this process (2 ATP molecules per one glucose molecule) [35]. Thus PKM supports the tumor growth by providing ATP. PKM2 is a variant of pyruvate kinase, produced by the alternative splicing of PKM pre-mRNA. PKM2 expression was found to be increased in various malignancies [36]. Lactate dehydrogenase converts pyruvate to lactate in anaerobic conditions. However tumor cells can produce excess amount of lactate under normoxic conditions. Increased levels of lactate induces the secretion of hyaluronan, thus promoting the metastasis of tumors [37]. Hypoxia inducing factor and c-Myc can induce the expression of lactate dehydrogenase A (LDHA) [38, 39]. LDHA silencing in HCT116 cancer cell line resulted in apoptosis of the cancer cells, which indicates the significance of LDHA in tumor growth and progression [40]. Thus, increased expression of PKM and LDHA in CACs might be resulting in the tumor cell survival by preventing the entry of glycolytic pathway into feedback inhibition loop by the end product of the pathway.

Hepatoma-derived growth factor (HDGF), a secreted protein which was first purified from the culture medium of Huh-7 hepatoma cells, was found to be up- 

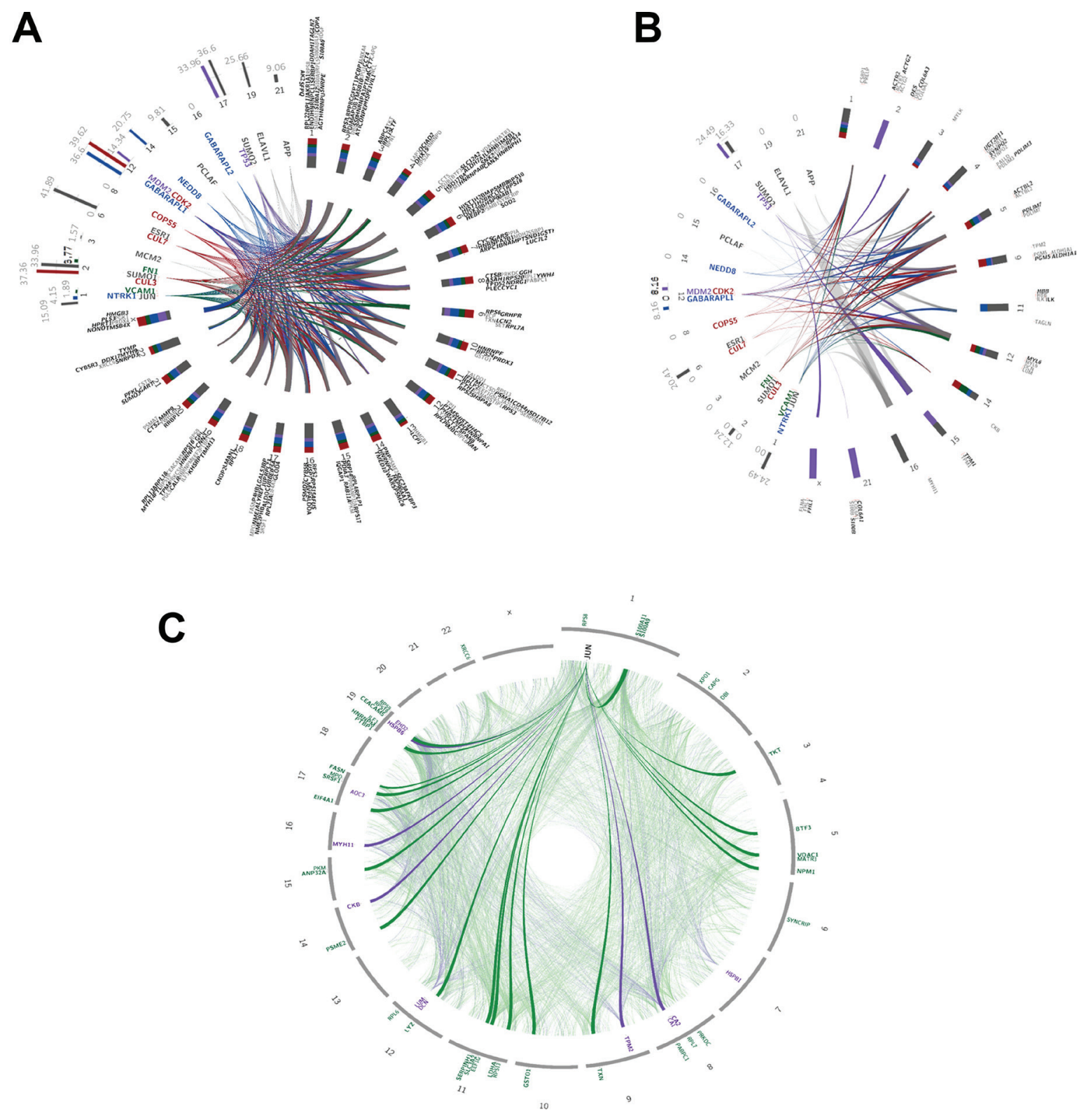

Figure 3: Interaction network analysis. Plot depicting the relationships and interactions between the (A) up-regulated (fold change from 1.5 and over) and (B) down-regulated (fold change from -1.5 and under) proteins identified using SM and TPP. Color-codes represent functions manually retrieved from the literature: grey = DNA and RNA regulation; green = immunological system functions; red = ubiquitin tagging; purple = cell cycle and p53 regulation; blue = neuronal regulation. (A) Inner circle lines connect between the 20 most common 1st-degree neighboring proteins ( $\sim 9$ to 12 hours; colored names) discovered by propagation analysis, and 241 up-regulated proteins ( $~ 12$ to 9 hours; grey hued names) identified by SM and TPP. Italic-bold names represent proteins up-regulated according to SM; bold according to TPP; regular according to both. Colored bar-plots ( $\sim 9$ to 12 hours) depict the relative active networks that the protein is part of according to MetaCore analysis, and their associated numbers represent the percentages of actual networks (from the total number of input networks). Colored stacked bar-plots ( $\sim 12$ to 9 hours) represent the relative contribution of each function to proteins gathered on the same chromosome. Integers are the chromosome numbers. (B) Inner circle lines connect between the 20 most common 1st-degree neighboring proteins $(\sim 7$ to 11 hours; colored names) discovered by propagation analysis, and 41 down-regulated proteins ( $\sim 12$ to 7 hours; grey hued names) identified by SM and TPP. Italic-bold names represent proteins down-regulated according to SM; bold according to TPP; regular according to both. Colored bar-plots ( $\sim 7$ to 11 hours) depict the relative active networks that the protein is part of according to MetaCore analysis, and their associated numbers represent the percentages of actual networks (from the total number of input networks). Colored stacked bar-plots ( 12 to 7 hours) represent the relative contribution of each function to proteins gathered on the same chromosome. Integers are the chromosome numbers. (C) JUN interaction network. Faded links represent interactions between the topmost 1st degree neighbors (identified via network propagation algorithm) and the prior 94 genes further filtered to include only genes with evidence from SM, TPP, and CPTAC. Bold links are prior genes linked directly to JUN; specifically, 21/44 up-regulated genes (fold change of 1.5 and over) and 5/11 down-regulated genes (fold change of -1.5 and under) are connected directly to JUN. Outer circle labels are the chromosomes' numbers; gene names are relatively positioned along the chromosomes. 
regulated in various cancers like hepatocellular carcinoma, colorectal, pancreatic and non-small cell lung cancers [41-44]. Expression of HDGF altered with changes in the expression of $\beta$-catenin and vice versa. HDGF knockdown in HCT116 cell lines resulted in the decreased cell proliferation by arresting the cells in G1 phase, finally leading to apoptosis. Besides the tumor growth, HDGF knock-down decreased the tumor cell migration and invasion in HCT116 cells [42]. Increased expression of HDGF was reported as a poor prognostic marker in various cancers like hepatocellular carcinoma, gastric and lung cancers [44-46]. HDGF was found to be up-regulated in CACs from the current study. HDGF could be potential target in CAC patients exhibiting increased tumor levels of this protein to improve the clinical outcomes.

Ribosomes are protein synthesizing machinery in the living cells, which are composed of rRNAs and ribosomal proteins (RPs). Besides maintaining the structural integrity of ribosomes by stabilizing folding of rRNAs, RPs are also involved in protein synthesis [47]. RPs are known to play extra ribosomal functions, which includes RNA splicing, DNA repair, cell survival, proto-oncogene regulation, tumor malignancy and differentiation [48]. Our study revealed that the colon tumor tissue exhibit increased expression of various ribosomal proteins associated with the smaller and larger subunits. RPs are reported to be dysregulated in cancers and various genetic disorders [49-54]. Kasai et al. identified increased expression of RPL7 using IHC in human CRCs, which has an endocrine function [55]. Proteins associated with tumor development and suppression like MYC and PTEN play a major role in the turnover of ribosomes by regulating the expression of RPs and S6K activity, respectively [47]. This indicates that the RPs differential expression is associated with tumorigenesis. Over-expression of RPS3a in NIH-3T3 cells resulted in the malignant transformation of the cells by inducing the expression of various anti-apoptotic proteins [56]. Increased expression level of RPS13 in gastric cancer cells protects the cells from drug induced apoptosis and enhances cell proliferation rates [57, 58]. RPS6, RPS19 and RPS25 helps in the transcription initiation of viral genes [59] while RPL5 and RPL11 acts as tumor suppressors by degrading the mRNA of c-myc, through RNA induced silencing complex (RISC) [60]. Thus RPs act as tumor suppressors and also promotes the tumor growth under different circumstances.

The proteins which showed down-regulation from this study were found to be involved in pathways related to focal adhesion and proteoglycans. Focal adhesion complexes are required for the cells to migrate from one region of the tissue to other. Filamin $\mathrm{A}$ and $\mathrm{C}$, and Caveolin 1 were found to be down-regulated by at least 2 folds while myosin regulatory light polypeptide 9 (MYL9) was found to be 4.5 fold down-regulated. The filamin family proteins acts as actin-binding proteins and play a role in compositing the actin cytoskeleton and associated cell surface adhesion proteins [61]. Filamin A has also been suggested to suppress cancer cell invasion and migration by regulating focal adhesion [62]. While the role of myosin regulatory light polypeptide 9 (MYL9) remains poorly documented in terms of its functional association in human cancers including colon carcinoma, a recent report by Yan et al., suggest lower expressions of MYL9 was associated with lower median survival rates in colon cancer patients [63]. Furthermore, the role of Caveolin 1 has been reported in multiple cancers towards both tumor progression and tumor suppression. However, in case of colon cancers, the association of Caveolin 1 expression with tumor progression has been variably reported [64-67]. Further studies should be carried out for understanding the decreased expression of focal adhesion proteins role in tumor growth and progression.

Proteoglycans are heavily glycosylated key molecules regulating the activity of several signalling pathways and the interactions between a cell and its microenvironment. Their polyhedic nature allows for their ability to interact with both ligands and receptors to regulate neoplastic growth, progression, and neovascularisation [68]. Over the years, the role of proteoglycans in cancer has been studied extensively. Heparan sulphate proteoglycans (HSPGs) are one such example that has a defined role as a proangiogenic factor by binding growth factors and exhibiting them to their cognate receptors $[68,69]$. Decorin is known to be a tumor suppressing gene involved in colon cancer and metastasis [70]. A large number of studies are focussing on considering Decorin as a molecule of high therapeutic potential in case of colon cancer $[70,71]$. Decorin deficient mice showed increased rate of tumor formation and poor cell differentiation [72]. It is found to be down-regulated in colorectal tumor tissues as compared to normal colon tissues $[72,73]$. The same trend was observed in this study as well wherein the expression of Decorin was 2-fold downregulated in colon tumor tissues. Lumican is a leucine rich proteoglycan present in the extracellular matrix. This protein has been reported to be up-regulated in breast, colorectal, pancreatic, uterine, cervical, and prostate cancers [74-78]. Ectopic expression of lumican in the prostate cancer cell lines showed, decreased cell proliferation, migration and invasion [78]. With increase in the stage of the breast tumors, the expression of lumican was decreased [79]. Decreased expression of lumican and decorin reported to be poor prognostic markers for node-negative invasive breast cancers [80]. In the present study, proteoglycans like decorin and lumican were down-regulated in CACs.

Another major group of proteins which were found to be dysregulated from this study includes the S100 protein family which consists of 21 distinct proteins sharing very high percentage of sequence and structural similarity. These proteins consist of two calcium binding motifs which are connected by a hinge/loop called target binding domain. These proteins act as $\mathrm{Ca}^{2+}$ sensors and regulate the intracellular calcium levels by sequestering 
them. Binding of calcium ions to the $\mathrm{S} 100$ proteins induces conformational change, which exposes the hydrophobic cleft for target binding to the hinge/target binding domain. Binding of the target to S100 protein enhances its affinity for calcium binding by 5-300 folds. These intracellular S100 proteins bind to various target proteins and regulate their activity. Extracellular S100 proteins bind to various cell surface receptors and facilitate intercellular communication. In most of the human cancers S100 family proteins are up-regulated. However, expression levels of these proteins also vary in different cancers based on the stage or subtype.

S100A8/A9 are associated with various biological functions including immune suppression, angiogenesis and pre-metastatic niche formation. Tumor cells induce production of S100A9 protein in the myeloid precursors, which prevents the differentiation of myeloid cells to macrophages and dendritic cells resulting in the development of myeloid-derived suppressor cells (MDSCs) in the tumor microenvironment. In this way tumor cells evade from the host immune system [81]. S100A8/A9 homo/heterodimers can interact with the tumor cell surface receptors like RAGE and TLR4 resulting in the activation of MAPK and NF- $\kappa$ B signalling pathways, which promotes tumor growth and invasion $[81,82]$. Various growth factors released from the primary tumor induce the expression of S100A8/A9 and creates a pro-inflammatory milieu, which facilitates the metastasis at the target site $[83,84]$.

Protein interaction analysis revealed the association of altered proteins in CACs with various transcriptional factors and their targets. NTRK1 (Neurotrophic Receptor Tyrosine Kinase 1; encodes TrkA) was previously reported to impose oncogenic activity in lung cancer cells by fusing with CD74 and, independently, with MPRIP [85]. Further, NTRK1 rearrangements were associated with metastatic CRC in clinical patients expressing TrkA [86]. SUMO1 and TP53 were found to be interrelated in colon cancer patients; Zhang et al. [87] have found SUMO1 to be significantly over-expressed in colon cancer patients, and that this over-expression leads to accumulation of P53 which in turn promotes colon tumor formation. JUN is a transcription factor that recognizes and binds to the enhancer heptamer motif 5-TGA[CG]TCA-3. It promotes activity of NR5A1 when phosphorylated by HIPK3; this leads to increased steroidogenic gene expression upon cAMP signaling pathway stimulation. It is also involved in activated KRAS-mediated transcriptional activation of USP2 8 and binds to the USP2 8 promoter in colorectal cancer cells [88]. A study by Suto et al. in 2004 also suggested that a dominant mutant of JUN inhibits the activity of the transcription factor AP-1 and is thus helpful for relieving colon cancer tumorigenesis [89]. Remarkably, JUN was also found to be the strongest and the only common protein after propagating the list of 94 proteins common to TPP and SM (Figure 3C).
The major strength of the present study lies in the usage of tumor and matched control specimens. This eliminates the person-to-person variation, due to their genetic makeup, lifestyle and environmental conditions. Despite using tumor specimens from the patients with different ethnic origin, the changes in the protein expression were consistent among the CAC patients. Due to the unavailability of large number of clinical sample, both discovery and validation were performed on small sample cohort, which is a major limitation of the present study. Synthetic peptide usage in the MRM experiments aids in the accurate quantification of peptides. MRM assays reported in the study were performed without synthetic peptides due to their unavailability; hence, relative abundance of the peptides for the significantly altered proteins was measured, instead of absolute quantification, which is the second limitation of the study. Significantly altered proteins identified from the present study can be further validated on larger patient cohorts and the significance of the altered proteins in the tumor growth/progression can be studied using cell line and animal models.

In conclusion, we have identified a few significantly altered proteins like ribosomal proteins, spliceosomal proteins, proteoglycans and various metabolic pathway enzymes which play a key role in the tumor development of CAC. Various transcriptional factors were found to be associated with the altered proteins. A panel of nine proteins, which were validated as differentially expressed proteins could be potential diagnostic markers for CACs. Further, validation of these proteins on larger patient cohorts would be useful in translating the bench side protein markers to bedside.

\section{MATERIALS AND METHODS}

\section{Tissue lysates and ethics statement}

CAC tissue lysates $(n=11)$ and their matched control tissue lysates (colon tissue specimens of same patient from a region distant from the site of tumor) were received from Department of Human Molecular Genetics \& Biochemistry, Sackler Medical School, Tel Aviv University, Israel, where the tissue samples were mechanically homogenized in a hypotonic lysis buffer containing $50 \mathrm{mM}$ Tris- $\mathrm{HCl}, \mathrm{pH} 7.5,1 \% \mathrm{NP} 40$, $150 \mathrm{mM} \mathrm{NaCl}, 0.1 \%$ SDS, $0.5 \%$ deoxycholic acid, $1 \mathrm{mM}$ EDTA supplied with protease inhibitor (Roche) and phosphatase inhibitor cocktails I and II (Sigma) [90]. Protein concentration was measured using Bio-Rad Protein Assay by iMARK Microplate reader (Bio-Rad). The sample details have been provided in Supplementary Table 1I. The further experiments were performed at Prof. Srivastava's laboratory at Indian Institute of Technology, Bombay (IIT-B) after receiving the approval from the institute ethics committee as per the proposal number IITB-IEC/2016/029. 


\section{Buffer exchange and in-solution protein digestion}

After quantification using Bradford's assay, $250 \mu \mathrm{g}$ of protein sample from tumor tissue lysates $(n=11)$ and their matched control tissue lysates $(n=11)$ were buffer exchanged with $0.5 \mathrm{M}$ Triethyl ammonium bicarbonate (TEAB) buffer followed by in-solution digestion of $75 \mu \mathrm{g}$ of protein as described previously [91].

\section{iTRAQ 4-plex labelling and off-gel fractionation}

The iTRAQ 4-plex labelling of the trypsin digested protein samples was done according to the manufacturer's instructions and the labelling strategy is illustrated in Figure 1A. Further, off-gel fractionation (3100 off-gel fractionator, Agilent) was performed on a high resolution (24 cm length) non-linear 3-10 $\mathrm{pH}$ range immobiline $\mathrm{pH}$ gradient (IPG) strips. The fractions were vacuum concentrated and desalted using C18 material packed ZipTips prior to LC-MS/MS data acquisition for the peptide samples.

\section{LC-MS/MS data acquisition and analysis using spectrum mill}

Mass spectrometry data acquisition was performed using Agilent 6550 iFunnel Q-TOF (Agilent Technologies) mass spectrometer equipped with chipcube interfaced nanoflow LC system (Agilent Technologies). The fractionated peptides were enriched on $\mathrm{C} 18$ enrichment column. The enriched peptides were separated on a $75 \mu \mathrm{m}$ x $150 \mathrm{~mm}$ analytical/separation column of polaris-high resolution-chip using a gradient mobile phase of $0.1 \%$ formic acid solution (Solvent A) and 90\% acetonitrile (Solvent B) at a flow rate of $0.5 \mu \mathrm{l} / \mathrm{min}$. The gradient method used over a period of $100 \mathrm{~min}$ for separation of peptides was: $0-2 \mathrm{~min}, 0-03 \%$ solvent $\mathrm{B} ; 2-70 \mathrm{~min}$, 03-35\% solvent B; 70-75 min, $35-45 \%$ solvent B; $75-85$ min, $45-95 \%$ solvent B; $85-88 \mathrm{~min}, 95-03 \%$ solvent B. From $88-100 \mathrm{~min}$, the enrichment and analytical columns were equilibrated with $03 \%$ solvent B and $97 \%$ solvent A, prior to the next peptide fraction run on the LC-MS system. Other parameters include nitrogen gas maintained at $250^{\circ} \mathrm{C}$ with a $9 \mathrm{~L} / \mathrm{min}$ flow rate; mass range of 300 $3000(\mathrm{~m} / \mathrm{z})$ in MS with a MS Scan rate of 8 spectra/sec; mass range of $50-3000(\mathrm{~m} / \mathrm{z})$ in MS/MS with a MS/ MS scan rate of 4 spectra/sec. From MS, top 12 intense peptides having a charge $\geq 2$ were selected for MS/MS and the mass spectral data was acquired in the centroid mode. The mass spectrometry data was analyzed using Spectrum Mill MS Proteomics Workbench software (Agilent Technologies); searched against SwissProt database using Homo sapiens as taxonomy; iTRAQ (N-term, K) $\&$ carbamidomethylation (C) as fixed modifications and oxidation of methionine as a variable modification with a precursor and product mass tolerance of 20 and $50 \mathrm{ppm}$, respectively. The mass spectrometry data files for the shotgun proteomics experiments have been deposited to the ProteomeXchange Consortium via the PRIDE [92] partner repository with the dataset identifier PXD006509.

\section{Mass spectrometry data analysis using Trans- Proteomic Pipeline}

The mass spectrometry raw files were converted into .mzXML format using MS convert version 3.0.5533 [93]. The converted files were searched against Homo sapiens database using comet version 2014.02 rev. 2 [94]. The UniProt Homo sapiens protein database contained 26,000 protein sequences and we also included decoy sequences (decoy sequences was generated using Decoy tool in Trans-Proteomic Pipeline by using "randomized sequences and interleave entries" decoy algorithm) and contaminant sequences from cRAP database (http://www. thegpm.org/crap/). The comet search parameters such as $25 \mathrm{ppm}$ peptide mass tolerance in peptide prophet, 1.0005 $\mathrm{m} / \mathrm{z}$ fragment bin tolerance, $0.4 \mathrm{~m} / \mathrm{z}$ monoisotopic offset, semi-digested trypsin termini with two allowed missed cleavage, carbamidomethylation of cysteine $(+57.021464$ $\mathrm{Da}$ ) and iTRAQ labeling on N-terminal and lysine $(+144.10206 \mathrm{Da})$ as a static modification and oxidation of methionine and tryptophan as variable modifications were used. Trans-Proteomic Pipeline (TPP) v5.0 typhoon was used for protein identification as well as for quantitation. PeptideProphet tool was used to assess the peptide spectral match (PSM) for individual files whereas iProphet tool was used to combine individual PeptideProphet files. Further, ProteinProphet was used for the identification of the proteins on the iProphet files and proteins with $1.0 \%$ FDR were considered as a true identification for protein quantitation [95-97]. The quantitation of each protein based on the iTRAQ reporter ion was measured using Libra algorithm in TPP module [21].

\section{Comparison of the expression levels of proteins identified from this study with the data available in literature}

Significantly altered proteins from this study were compared against the list of proteins identified to be dysregulated in the study at CPTAC portal [24]. Further, the expression levels of these proteins in colorectal tumors available at the Human Protein Atlas was compared to shortlist the targets for validation.

\section{Bioinformatics analysis}

The iTRAQ data was subjected to bioinformatic analysis using the DAVID Functional Annotation Bioinformatics Analysis v6.8 to identify the pathways affected in the colon adenocarcinoma. 
An enrichment analysis of the common differentially expressed proteins identified from iTRAQ analysis using Spectrum Mill and Trans-Proteomic Pipeline together with their fold changes was performed using MetaCore version 6.30, build 68780 (Thomson Reuters). Thereby, the top ten statistically enriched pathway maps, process networks, diseases (by biomarkers) and GO Processes were identified for the up-, and the down-regulated proteins separately, and then for all dysregulated proteins together.

In addition, the MetaCore "Interactions by Protein Functions" tool was applied with a FDR threshold of 0.05 to identify proteins that are functionally over-connected with proteins (up-, down-regulated and all dysregulated proteins) in the data set.

Furthermore, MetaCore was used to identify transcription factors for which targets are enriched in the data set (up-, down-regulated and all dysregulated proteins) with a FDR threshold of 0.05 .

We used the network propagation method by Vanunu et al. 2010 [27] for the identification of disease-relevant proteins. The algorithm was given a list of known disease genes to be used as prior knowledge, and it simulated a diffusion process over the HIPPIE protein-protein network [28] by iteratively applying the formula:

$$
F^{t}:=\alpha W^{\prime} F^{t-1}+(1-\alpha) Y
$$

where $F$ is a prioritization function which reflects the relevance of all proteins in the network to the disease, $W$ ' is a matrix whose values are the normalized confidence scores of the network edges, $Y$ is the prior knowledge vector (which in our case contains ' 1 's for known diseaserelevant proteins and ' 0 's for other proteins), $t$ is a given time point, and $\alpha \in(0,1)$ weighs the relative importance of the network and prior knowledge terms. More details can be found in the study by Vanunu et al. 2010 [27].

\section{Validation by western blot}

Of the 11 paired samples used for shotgun experiments, colon adenocarcinoma tissue lysates from seven individuals and their corresponding matched control tissue lysates were used for the validation of S100A9 using western blotting (WB) method. Blocking of membrane was done using 5\% BSA in TBST at RT followed by overnight incubation with 1:1000 dilution of polyclonal primary antibody against S100A9 at $4^{\circ} \mathrm{C}$. The blot was incubated with 1:3000 dilution of secondary antibody conjugated with HRP (GeNei (MERCK)-621140380011730 or 621140680011730). A chromogenic substance, TMB/H2O2 (GeNei) was used for visualization of protein bands and the target protein bands were normalized against the uniform intensity band (approx. $70 \mathrm{kDa}$ ) in the ponceau image of the blot. Quantitation of the S100A9 protein was performed using ImageQuantTL software version 5.0 (GE Healthcare).

\section{MRM based validation}

Validation of significantly altered proteins was done using multiple reaction monitoring (MRM) method, where ten tumor and matched control lysates (subset of the 11 samples used for shotgun experiments) were trypsin digested $(96 \mu \mathrm{g}$ each) and reconstituted in $50 \mu \mathrm{l}$ of $0.1 \%$ formic acid. The MRM assay was performed using LCMS 8050 triple quadrupole (QQQ) mass spectrometer (Shimadzu) coupled with Nexera UHPLC. For each protein at least three peptides and for each peptide minimum three transitions were monitored. Peptides were analysed on QQQ in the MRM mode with dwell time of $0.005 \mathrm{sec}$ and a $0.003 \mathrm{sec}$ pause time for every transition. All transitions were scheduled using a retention time window of \pm 1 minute. The list of the peptide sequences and their retention times for nine proteins monitored using MRM has been provided in Supplementary Table 1F. A total of 138 transitions were monitored using a single method file. Each sample was run in triplicates (injection volume $-3 \times 5 \mathrm{ul}$ ) with a run time of 18 minutes each. For acquisition of data in MRM mode following parameters were used: Q1 resolution, 0.7 FWHM, Q3 resolution, 0.7 FWHM; with a collision gas pressure of $270 \mathrm{kPa}$. Peptides separation was done on a Shim-pack XR-ODS II (75 mm L $\times 3$ mm I.D.; $2.2 \mu \mathrm{m}$ ) column, using linear gradient of $0.1 \%$ formic acid in milli Q water (solvent $\mathrm{A}$ ) and acetonitrile/water at a flow rate of $0.4 \mathrm{ml} / \mathrm{min}$ with the following gradient method: $0.01-1.5 \mathrm{~min} ., 3 \%$ solvent B; 1.5-10 min., 3-50\% solvent B; 10-11 min., 50-95\% solvent B; 11-14 min., 95\% solvent B; 14-14.1 min., 953\% solvent B; 14.1-18 min., 3\% solvent B. MRM data was analysed using Skyline software version 3.6 [98] to validate the significantly dysregulated proteins.

\section{Abbreviations}

CAC: Colon Adenocarcinoma; iTRAQ: Isobaric Tagging for Relative and Absolute Quantification; LC-MS/MS: Liquid Chromatography-Tandem Mass Spectrometry; MRM: Multiple Reaction Monitoring; TPP: Trans-Proteomic Pipeline; HPA: Human Protein Atlas; CPTAC: Clinical Proteome Tumor Analysis Consortium; SM: Spectrum Mill.

\section{Author contributions}

The experimental plan was conceived and designed by AA and SS. The experiments and data analysis were performed by AA, SK and KG. TPP data analysis was performed by PJR. The clinical samples used in the study collected and processed by $\mathrm{DH}, \mathrm{MD}$ and GA. The processed samples were provided by GA as a part of the Indo-Israel joint project between GA and SS. Networks and Interactors were generated and analysed by RL, SBS, AH, AHW, HB, RS and GA. SR and AS helped in 
acquiring and analyzing MRM data. All the authors have contributed toward writing and editing the manuscript.

\section{CONFLICTS OF INTEREST}

The authors declare no competing financial interests.

\section{FUNDING}

We would like to acknowledge University Grants Commission for funding this work through the Indo-Israel Joint Program (Project code: F.6-17/2014) granted to SS.

\section{REFERENCES}

1. Torre LA, Bray F, Siegel RL, Ferlay J, Lortet-Tieulent J, Jemal A. Global cancer statistics, 2012. CA: a cancer journal for clinicians. 2015; 65:87-108.

2. Gonzalez-Pons M, Cruz-Correa M. Colorectal Cancer Biomarkers: Where Are We Now? BioMed research international. 2015; 2015:149014.

3. Rasool S, Kadla SA, Rasool V, Ganai BA. A comparative overview of general risk factors associated with the incidence of colorectal cancer. Tumour biology. 2013; 34:2469-2476.

4. Yiu AJ, Yiu CY. Biomarkers in Colorectal Cancer. Anticancer research. 2016; 36:1093-1102.

5. Gupta AK, Brenner DE, Turgeon DK. Early detection of colon cancer: new tests on the horizon. Molecular diagnosis \& therapy. 2008; 12:77-85.

6. Werling RW, Yaziji H, Bacchi CE, Gown AM. CDX2, a highly sensitive and specific marker of adenocarcinomas of intestinal origin: an immunohistochemical survey of 476 primary and metastatic carcinomas. The American journal of surgical pathology. 2003; 27:303-310.

7. Hanski C, Hofmeier M, Schmitt-GraffA, Riede E, Hanski ML, Borchard F, Sieber E, Niedobitek F, Foss HD, Stein H, Riecken EO. Overexpression or ectopic expression of MUC2 is the common property of mucinous carcinomas of the colon, pancreas, breast, and ovary. The Journal of pathology. 1997; 182:385-391.

8. Magnusson $\mathrm{K}$, de Wit M, Brennan DJ, Johnson LB, McGee SF, Lundberg E, Naicker K, Klinger R, Kampf C, Asplund A, Wester K, Gry M, Bjartell A, et al. SATB2 in combination with cytokeratin 20 identifies over $95 \%$ of all colorectal carcinomas. The American journal of surgical pathology. 2011; 35:937-948.

9. Vang R, Gown AM, Barry TS, Wheeler DT, Yemelyanova A, Seidman JD, Ronnett BM. Cytokeratins 7 and 20 in primary and secondary mucinous tumors of the ovary: analysis of coordinate immunohistochemical expression profiles and staining distribution in 179 cases. The American journal of surgical pathology. 2006; 30:1130-1139.
10. Wauters CC, Smedts F, Gerrits LG, Bosman FT, Ramaekers FC. Keratins 7 and 20 as diagnostic markers of carcinomas metastatic to the ovary. Human pathology. 1995; 26:852-855.

11. Clevers H. Wnt/beta-catenin signaling in development and disease. Cell. 2006; 127:469-480.

12. Zhou M, Chinnaiyan AM, Kleer CG, Lucas PC, Rubin MA. Alpha-Methylacyl-CoA racemase: a novel tumor marker over-expressed in several human cancers and their precursor lesions. The American journal of surgical pathology. 2002; 26:926-931.

13. Chen ZE, Lin F. Application of immunohistochemistry in gastrointestinal and liver neoplasms: new markers and evolving practice. Archives of pathology \& laboratory medicine. 2015; 139:14-23.

14. Panarelli NC, Yantiss RK, Yeh MM, Liu Y, Chen YT. Tissue-specific cadherin CDH17 is a useful marker of gastrointestinal adenocarcinomas with higher sensitivity than CDX2. American journal of clinical pathology. 2012; 138:211-222.

15. Bae JM, Lee TH, Cho NY, Kim TY, Kang GH. Loss of CDX2 expression is associated with poor prognosis in colorectal cancer patients. World journal of gastroenterology. 2015; 21:1457-1467.

16. Chen CC, Yang SH, Lin JK, Lin TC, Chen WS, Jiang JK, Wang HS, Chang SC. Is it reasonable to add preoperative serum level of CEA and CA19-9 to staging for colorectal cancer? The Journal of surgical research. 2005; 124:169-174.

17. Kim JC, Lee KH, Yu CS, Kim HC, Kim JR, Chang HM, Kim JH, Kim JS, Kim TW. The clinicopathological significance of inferior mesenteric lymph node metastasis in colorectal cancer. European journal of surgical oncology. 2004; 30:271-279.

18. Weissenberger C, Von Plehn G, Otto F, Barke A, Momm F, Geissler M. Adjuvant radiochemotherapy of stage II and III rectal adenocarcinoma: role of CEA and CA 19-9. Anticancer research. 2005; 25:1787-1793.

19. Park YJ, Park KJ, Park JG, Lee KU, Choe KJ, Kim JP. Prognostic factors in 2230 Korean colorectal cancer patients: analysis of consecutively operated cases. World journal of surgery. 1999; 23:721-726.

20. Locker GY, Hamilton S, Harris J, Jessup JM, Kemeny N, Macdonald JS, Somerfield MR, Hayes DF, Bast RC Jr, Asco. ASCO 2006 update of recommendations for the use of tumor markers in gastrointestinal cancer. Journal of clinical oncology. 2006; 24:5313-5327.

21. Deutsch EW, Mendoza L, Shteynberg D, Farrah T, Lam H, Tasman N, Sun Z, Nilsson E, Pratt B, Prazen B, Eng JK, Martin DB, Nesvizhskii AI, Aebersold R. A guided tour of the Trans-Proteomic Pipeline. Proteomics. 2010; 10:1150-1159.

22. Jankova L, Chan C, Fung CL, Song X, Kwun SY, Cowley MJ, Kaplan W, Dent OF, Bokey EL, Chapuis PH, Baker MS, Robertson GR, Clarke SJ, Molloy MP. Proteomic comparison of colorectal tumours and non-neoplastic 
mucosa from paired patient samples using iTRAQ mass spectrometry. Molecular bioSystems. 2011; 7:2997-3005.

23. Wisniewski JR, Ostasiewicz P, Dus K, Zielinska DF, Gnad F, Mann M. Extensive quantitative remodeling of the proteome between normal colon tissue and adenocarcinoma. Molecular systems biology. 2012; 8:611.

24. Zhang B, Wang J, Wang X, Zhu J, Liu Q, Shi Z, Chambers MC, Zimmerman LJ, Shaddox KF, Kim S, Davies SR, Wang S, Wang P, et al. Proteogenomic characterization of human colon and rectal cancer. Nature. 2014; 513:382-387.

25. Huang da W, Sherman BT, Lempicki RA. Bioinformatics enrichment tools: paths toward the comprehensive functional analysis of large gene lists. Nucleic acids research. 2009; 37:1-13.

26. Huang da W, Sherman BT, Lempicki RA. Systematic and integrative analysis of large gene lists using DAVID bioinformatics resources. Nature protocols. 2009; 4:44-57.

27. Vanunu O, Magger O, Ruppin E, Shlomi T, Sharan R. Associating genes and protein complexes with disease via network propagation. PLoS computational biology. 2010; 6:e1000641.

28. Schaefer MH, Fontaine JF, Vinayagam A, Porras P, Wanker EE, Andrade-Navarro MA. HIPPIE: Integrating protein interaction networks with experiment based quality scores. PloS one. 2012; 7:e31826.

29. Alvarez-Chaver P, Otero-Estevez O, Paez de la Cadena M, Rodriguez-Berrocal FJ, Martinez-Zorzano VS. Proteomics for discovery of candidate colorectal cancer biomarkers. World journal of gastroenterology. 2014; 20:3804-3824.

30. Fung KY, Tabor B, Buckley MJ, Priebe IK, Purins L, Pompeia C, Brierley GV, Lockett T, Gibbs P, Tie J, McMurrick P, Moore J, Ruszkiewicz A, et al. Blood-based protein biomarker panel for the detection of colorectal cancer. PloS one. 2015; 10:e120425.

31. Jones JJ, Wilcox BE, Benz RW, Babbar N, Boragine G, Burrell T, Christie EB, Croner LJ, Cun P, Dillon R, Kairs $\mathrm{SN}$, Kao A, Preston R, et al. A Plasma-Based Protein Marker Panel for Colorectal Cancer Detection Identified by Multiplex Targeted Mass Spectrometry. Clinical colorectal cancer. 2016; 15:186-194 e113.

32. Blume JE, Wilhelmsen M, Benz RW, Brünner N, Christensen IJ, Croner LJ, Dillon R, Hillig T, Jones JJ, Jørgensen LN, Kao A, Klaerke M, Laurberg S, et al. Discovery, Validation of Plasma-Protein Biomarker Panels for the Detection of Colorectal Cancer and Advanced Adenoma in a Danish Collection of Samples from Patients Referred for Diagnostic Colonoscopy. The Journal of Applied Laboratory Medicine: An AACC Publication. 2016; 1:181-193.

33. Talaiezadeh A, Shahriari A, Tabandeh MR, Fathizadeh P, Mansouri S. Kinetic characterization of lactate dehydrogenase in normal and malignant human breast tissues. Cancer cell international. 2015; 15:19.

34. Gatenby RA, Gillies RJ. Why do cancers have high aerobic glycolysis? Nature reviews Cancer. 2004; 4:891-899.
35. Yang W, Lu Z. Regulation and function of pyruvate kinase M2 in cancer. Cancer letters. 2013; 339:153-158.

36. Mazurek S, Boschek CB, Hugo F, Eigenbrodt E. Pyruvate kinase type M2 and its role in tumor growth and spreading. Seminars in cancer biology. 2005; 15:300-308.

37. Hirschhaeuser F, Sattler UG, Mueller-Klieser W. Lactate: a metabolic key player in cancer. Cancer research. 2011; 71:6921-6925.

38. Shim H, Dolde C, Lewis BC, Wu CS, Dang G, Jungmann RA, Dalla-Favera R, Dang CV. c-Myc transactivation of LDH-A: implications for tumor metabolism and growth. Proceedings of the National Academy of Sciences of the United States of America. 1997; 94:6658-6663.

39. Cui XG, Han ZT, He SH, Wu XD, Chen TR, Shao CH, Chen DL, Su N, Chen YM, Wang T, Wang J, Song DW, Yan WJ, et al. HIF1/2alpha mediates hypoxia-induced LDHA expression in human pancreatic cancer cells. Oncotarget. 2017; 8:24840 24852. https://doi.org/10.18632/oncotarget.15266.

40. Allison SJ, Knight JR, Granchi C, Rani R, Minutolo F, Milner J, Phillips RM. Identification of LDH-A as a therapeutic target for cancer cell killing via (i) p53/NAD(H)-dependent and (ii) p53-independent pathways. Oncogenesis. 2014; 3:e102.

41. Hu TH, Huang CC, Liu LF, Lin PR, Liu SY, Chang HW, Changchien CS, Lee CM, Chuang JH, Tai MH. Expression of hepatoma-derived growth factor in hepatocellular carcinoma. Cancer. 2003; 98:1444-1456.

42. Lian J, Tang J, Shi H, Li H, Zhen T, Xie W, Zhang F, Yang Y, Han A. Positive feedback loop of hepatoma-derived growth factor and beta-catenin promotes carcinogenesis of colorectal cancer. Oncotarget. 2015; 6:29357-29374. https://doi.org/10.18632/oncotarget.4982.

43. Uyama H, Tomita Y, Nakamura H, Nakamori S, Zhang B, Hoshida Y, Enomoto H, Okuda Y, Sakon M, Aozasa K, Kawase I, Hayashi N, Monden M. Hepatoma-derived growth factor is a novel prognostic factor for patients with pancreatic cancer. Clinical cancer research. 2006; 12:6043-6048.

44. Ren H, Tang X, Lee JJ, Feng L, Everett AD, Hong WK, Khuri FR, Mao L. Expression of hepatoma-derived growth factor is a strong prognostic predictor for patients with early-stage non-small-cell lung cancer. Journal of clinical oncology. 2004; 22:3230-3237.

45. Yoshida K, Tomita Y, Okuda Y, Yamamoto S, Enomoto H, Uyama H, Ito H, Hoshida Y, Aozasa K, Nagano H, Sakon M, Kawase I, Monden M, Nakamura H. Hepatoma-derived growth factor is a novel prognostic factor for hepatocellular carcinoma. Annals of surgical oncology. 2006; 13:159-167.

46. Yamamoto S, Tomita Y, Hoshida Y, Takiguchi S, Fujiwara Y, Yasuda T, Doki Y, Yoshida K, Aozasa K, Nakamura H, Monden M. Expression of hepatoma-derived growth factor is correlated with lymph node metastasis and prognosis of gastric carcinoma. Clinical cancer research. 2006; 12:117-122.

47. Ruggero D, Pandolfi PP. Does the ribosome translate cancer? Nature reviews Cancer. 2003; 3:179-192. 
48. Wool IG. Extraribosomal functions of ribosomal proteins. Trends in biochemical sciences. 1996; 21:164-165.

49. Kim JH, You KR, Kim IH, Cho BH, Kim CY, Kim DG. Over-expression of the ribosomal protein L36a gene is associated with cellular proliferation in hepatocellular carcinoma. Hepatology. 2004; 39:129-138.

50. Wang Q, Yang C, Zhou J, Wang X, Wu M, Liu Z. Cloning and characterization of full-length human ribosomal protein L15 cDNA which was overexpressed in esophageal cancer. Gene. 2001; 263:205-209.

51. Cheng Q, Lau WM, Chew SH, Ho TH, Tay SK, Hui KM. Identification of molecular markers for the early detection of human squamous cell carcinoma of the uterine cervix. British journal of cancer. 2002; 86:274-281.

52. Henry JL, Coggin DL, King CR. High-level expression of the ribosomal protein L19 in human breast tumors that overexpress erbB-2. Cancer research. 1993; 53:1403-1408.

53. Pellagatti A, Hellstrom-Lindberg E, Giagounidis A, Perry J, Malcovati L, Della Porta MG, Jadersten M, Killick S, Fidler C, Cazzola M, Wainscoat JS, Boultwood J. Haploinsufficiency of RPS14 in 5q- syndrome is associated with deregulation of ribosomal- and translation-related genes. British journal of haematology. 2008; 142:57-64.

54. Rujkijyanont P, Adams SL, Beyene J, Dror Y. Bone marrow cells from patients with Shwachman-Diamond syndrome abnormally express genes involved in ribosome biogenesis and RNA processing. British journal of haematology. 2009; 145:806-815.

55. Kasai H, Nadano D, Hidaka E, Higuchi K, Kawakubo M, Sato TA, Nakayama J. Differential expression of ribosomal proteins in human normal and neoplastic colorectum. The journal of histochemistry and cytochemistry. 2003; 51:567-574.

56. Naora H, Takai I, Adachi M, Naora H. Altered cellular responses by varying expression of a ribosomal protein gene: sequential coordination of enhancement and suppression of ribosomal protein S3a gene expression induces apoptosis. The Journal of cell biology. 1998; 141:741-753.

57. Shi Y, Zhai H, Wang X, Han Z, Liu C, Lan M, Du J, Guo C, Zhang Y, Wu K, Fan D. Ribosomal proteins S13 and L23 promote multidrug resistance in gastric cancer cells by suppressing drug-induced apoptosis. Experimental cell research. 2004; 296:337-346.

58. Guo X, Shi Y, Gou Y, Li J, Han S, Zhang Y, Huo J, Ning X, Sun L, Chen Y, Sun S, Fan D. Human ribosomal protein S13 promotes gastric cancer growth through down-regulating p27(Kip1). Journal of cellular and molecular medicine. 2011; 15:296-306.

59. Zhou X, Liao WJ, Liao JM, Liao P, Lu H. Ribosomal proteins: functions beyond the ribosome. Journal of molecular cell biology. 2015; 7:92-104.

60. Liao JM, Zhou X, Gatignol A, Lu H. Ribosomal proteins L5 and L11 co-operatively inactivate c-Myc via RNA-induced silencing complex. Oncogene. 2014; 33:4916-4923.
61. Razinia Z, Makela T, Ylanne J, Calderwood DA. Filamins in mechanosensing and signaling. Annual review of biophysics. 2012; 41:227-246.

62. Xu Y, Bismar TA, Su J, Xu B, Kristiansen G, Varga Z, Teng L, Ingber DE, Mammoto A, Kumar R, Alaoui-Jamali MA. Filamin A regulates focal adhesion disassembly and suppresses breast cancer cell migration and invasion. The Journal of experimental medicine. 2010; 207:2421-2437.

63. Yan Z, Li J, Xiong Y, Xu W, Zheng G. Identification of candidate colon cancer biomarkers by applying a random forest approach on microarray data. Oncology reports. 2012; 28:1036-1042.

64. Joshi B, Strugnell SS, Goetz JG, Kojic LD, Cox ME, Griffith OL, Chan SK, Jones SJ, Leung SP, Masoudi H, Leung S, Wiseman SM, Nabi IR. Phosphorylated caveolin-1 regulates Rho/ROCK-dependent focal adhesion dynamics and tumor cell migration and invasion. Cancer research. 2008; 68:8210-8220.

65. Patlolla JM, Swamy MV, Raju J, Rao CV. Overexpression of caveolin-1 in experimental colon adenocarcinomas and human colon cancer cell lines. Oncology reports. 2004; 11:957-963.

66. Fine SW, Lisanti MP, Galbiati F, Li M. Elevated expression of caveolin-1 in adenocarcinoma of the colon. American journal of clinical pathology. 2001; 115:719-724.

67. Bender FC, Reymond MA, Bron C, Quest AF. Caveolin-1 levels are down-regulated in human colon tumors, and ectopic expression of caveolin-1 in colon carcinoma cell lines reduces cell tumorigenicity. Cancer research. 2000; 60:5870-5878.

68. Iozzo RV, Sanderson RD. Proteoglycans in cancer biology, tumour microenvironment and angiogenesis. Journal of cellular and molecular medicine. 2011; 15:1013-1031.

69. Wade A, Robinson AE, Engler JR, Petritsch C, James CD, Phillips JJ. Proteoglycans and their roles in brain cancer. The FEBS journal. 2013; 280:2399-2417.

70. Jarvinen TA, Prince S. Decorin: A Growth Factor Antagonist for Tumor Growth Inhibition. BioMed research international. 2015; 2015:654765.

71. Nyman MC, Sainio AO, Pennanen MM, Lund RJ, Vuorikoski S, Sundstrom JT, Jarvelainen HT. Decorin in Human Colon Cancer: Localization In Vivo and Effect on Cancer Cell Behavior In Vitro. The journal of histochemistry and cytochemistry : official journal of the Histochemistry Society. 2015; 63:710-720.

72. Bi X, Tong C, Dockendorff A, Bancroft L, Gallagher L, Guzman G, Iozzo RV, Augenlicht LH, Yang W. Genetic deficiency of decorin causes intestinal tumor formation through disruption of intestinal cell maturation. Carcinogenesis. 2008; 29:1435-1440.

73. Suhovskih AV, Aidagulova SV, Kashuba VI, Grigorieva EV. Proteoglycans as potential microenvironmental biomarkers for colon cancer. Cell and tissue research. 2015; 361:833-844. 
74. Leygue E, Snell L, Dotzlaw H, Hole K, Hiller-Hitchcock T, Roughley PJ, Watson PH, Murphy LC. Expression of lumican in human breast carcinoma. Cancer research. 1998; 58:1348-1352.

75. Seya T, Tanaka N, Shinji S, Yokoi K, Koizumi M, Teranishi N, Yamashita K, Tajiri T, Ishiwata T, Naito Z. Lumican expression in advanced colorectal cancer with nodal metastasis correlates with poor prognosis. Oncology reports. 2006; 16:1225-1230.

76. Ping Lu Y, Ishiwata T, Asano G. Lumican expression in alpha cells of islets in pancreas and pancreatic cancer cells. The Journal of pathology. 2002; 196:324-330.

77. Naito Z, Ishiwata T, Kurban G, Teduka K, Kawamoto Y, Kawahara K, Sugisaki Y. Expression and accumulation of lumican protein in uterine cervical cancer cells at the periphery of cancer nests. International journal of oncology. 2002; 20:943-948.

78. Coulson-Thomas VJ, Coulson-Thomas YM, Gesteira TF, Andrade de Paula CA, Carneiro CR, Ortiz V, Toma L, Kao WW, Nader HB. Lumican expression, localization and antitumor activity in prostate cancer. Experimental cell research. 2013; 319:967-981.

79. Panis C, Pizzatti L, Herrera AC, Cecchini R, Abdelhay E. Putative circulating markers of the early and advanced stages of breast cancer identified by high-resolution labelfree proteomics. Cancer letters. 2013; 330:57-66.

80. Troup S, Njue C, Kliewer EV, Parisien M, Roskelley C, Chakravarti S, Roughley PJ, Murphy LC, Watson PH. Reduced expression of the small leucine-rich proteoglycans, lumican, and decorin is associated with poor outcome in node-negative invasive breast cancer. Clinical cancer research. 2003; 9:207-214.

81. Ichikawa M, Williams R, Wang L, Vogl T, Srikrishna G. S100A8/A9 activate key genes and pathways in colon tumor progression. Molecular cancer research. 2011; 9:133-148.

82. Yin C, Li H, Zhang B, Liu Y, Lu G, Lu S, Sun L, Qi Y, Li X, Chen W. RAGE-binding S100A8/A9 promotes the migration and invasion of human breast cancer cells through actin polymerization and epithelial-mesenchymal transition. Breast cancer research and treatment. 2013; 142:297-309.

83. Hiratsuka S, Watanabe A, Aburatani H, Maru Y. Tumourmediated upregulation of chemoattractants and recruitment of myeloid cells predetermines lung metastasis. Nature cell biology. 2006; 8:1369-1375.

84. Hiratsuka S, Watanabe A, Sakurai Y, Akashi-Takamura S, Ishibashi S, Miyake K, Shibuya M, Akira S, Aburatani H, Maru Y. The S100A8-serum amyloid A3-TLR4 paracrine cascade establishes a pre-metastatic phase. Nature cell biology. 2008; 10:1349-1355.

85. Vaishnavi A, Capelletti M, Le AT, Kako S, Butaney M, Ercan D, Mahale S, Davies KD, Aisner DL, Pilling AB, Berge EM, Kim J, Sasaki H, et al. Oncogenic and drugsensitive NTRK1 rearrangements in lung cancer. Nature medicine. 2013; 19:1469-1472.
86. Lee SJ, Li GG, Kim ST, Hong ME, Jang J, Yoon N, Ahn SM, Murphy D, Christiansen J, Wei G, Hornby Z, Lee DW, Park JO, et al. NTRK1 rearrangement in colorectal cancer patients: evidence for actionable target using patientderived tumor cell line. Oncotarget. 2015; 6:39028-39035. https://doi.org/10.18632/oncotarget.5494.

87. Zhang H, Kuai X, Ji Z, Li Z, Shi R. Over-expression of small ubiquitin-related modifier-1 and sumoylated p53 in colon cancer. Cell Biochem Biophys. 2013; 67:1081-87.

88. Serra RW, Fang M, Park SM, Hutchinson L, Green MR. A KRAS-directed transcriptional silencing pathway that mediates the CpG island methylator phenotype. eLife. 2014; 3:e02313.

89. Suto R, Tominaga K, Mizuguchi H, Sasaki E, Higuchi K, Kim S, Iwao H, Arakawa T. Dominant-negative mutant of c-Jun gene transfer: a novel therapeutic strategy for colorectal cancer. Gene therapy. 2004; 11:187-193.

90. Hollander D, Donyo M, Atias N, Mekahel K, Melamed Z, Yannai S, Lev-Maor G, Shilo A, Schwartz S, Barshack I, Sharan R, Ast G. A network-based analysis of colon cancer splicing changes reveals a tumorigenesis-favoring regulatory pathway emanating from ELK1. Genome research. 2016; 26:541-553.

91. Gollapalli K, Ghantasala S, Kumar S, Srivastava R, Rapole S, Moiyadi A, Epari S, Srivastava S. Subventricular zone involvement in Glioblastoma-A proteomic evaluation and clinicoradiological correlation. Scientific reports. 2017; 7:1449.

92. Vizcaino JA, Csordas A, del-Toro N, Dianes JA, Griss J, Lavidas I, Mayer G, Perez-Riverol Y, Reisinger F, Ternent T, Xu QW, Wang R, Hermjakob H. 2016 update of the PRIDE database and its related tools. Nucleic acids research. 2016; 44:D447-456.

93. Kessner D, Chambers M, Burke R, Agus D, Mallick P. ProteoWizard: open source software for rapid proteomics tools development. Bioinformatics. 2008; 24:2534-2536.

94. Eng JK, Jahan TA, Hoopmann MR. Comet: an open-source MS/ MS sequence database search tool. Proteomics. 2013; 13:22-24.

95. Deutsch EW, Mendoza L, Shteynberg D, Slagel J, Sun Z, Moritz RL. Trans-Proteomic Pipeline, a standardized data processing pipeline for large-scale reproducible proteomics informatics. Proteomics Clinical applications. 2015; 9:745-754.

96. Shteynberg D, Deutsch EW, Lam H, Eng JK, Sun Z, Tasman N, Mendoza L, Moritz RL, Aebersold R, Nesvizhskii AI. iProphet: multi-level integrative analysis of shotgun proteomic data improves peptide and protein identification rates and error estimates. Molecular \& cellular proteomics. 2011; 10:M111 007690.

97. Nesvizhskii AI, Keller A, Kolker E, Aebersold R. A statistical model for identifying proteins by tandem mass spectrometry. Analytical chemistry. 2003; 75:4646-4658.

98. MacLean B, Tomazela DM, Shulman N, Chambers M, Finney GL, Frewen B, Kern R, Tabb DL, Liebler DC, MacCoss MJ. Skyline: an open source document editor for creating and analyzing targeted proteomics experiments. Bioinformatics. 2010; 26:966-968. 